\title{
A Rosa do Mato, de Cruz e Silva: um conto ovidiano
}

Mariana Gois Neves Universidade de Friburgo-Suíça

\begin{abstract}
Resumo: Neste trabalho, faz-se uma análise diferencial entre a Metamorphose VIII de Cruz e Silva (1731-1799), intitulada Rosa do Mato, e a fábula Píramo e Tisbé, do Livro IV das Metamorfoses de Ovidio. O objectivo é saber qual o contexto que presidiu à elaboração da Rosa do Mato, as motivaçôes que levaram o poeta português a distanciar-se do modelo latino. Os aspectos analisados incidem no processo de encadeamento narrativo de cada uma das histórias ou nas técnicas narrativas adoptadas, no cenário, neste caso a Babilónia e a floresta brasileira; no estatuto das personagens; na voz do narrador, sem esquecer o desenlace finale o significado da metamorfose em ambos textos. Como conclusão, falar-se-á do contexto vivencial de Cruze Silva e das influências que determinaram as suas opçôes, respectivamente as suas estadias no Brasil e o cruzamento do romantismo brasileiro com o neoclassicismo e com a lírica peninsular medieval.

Palavras-chave: Ovidio, Cruz e Silva, Arcádia lusitana
\end{abstract}

\begin{abstract}
As Metamorphoses do português Cruz e Silva (1731-1799), um dos fundadores da Arcádia Lusitana, consiste num conjunto de doze poemas decassilábicos de inspiração ovidiana que contam histórias de amor infelizes e cujas personagens se transformam, no fim, em pedras, plantas ou pássaros, todos
\end{abstract}


eles de origem brasileira. A rapariga apaixonada e metamorfoseada após um desgosto de amor e a mudança de cor das flores são portanto elementos do poeta português inspirados no autor latino.

Neste sentido, procurar-se-ão examinar, neste breve estudo, as dissemelhanças entre a Metamorphose VIII, de Cruz e Silva, intitulada Rosa do Mato, e a fábula Píramo e Tisbé, incluída no Livro IV das Metamorfoses de Ovídio. O objectivo é saber qual o contexto que presidiu à elaboração da Rosa do Mato e o público ao qual ele se dirige, saber como se distancia Cruz e Silva do seu modelo de referência. Seria igualmente interessante analisar todas as Metamorphoses deste autor para podermos melhor identificar o dialogismo entre ambos os poetas, mas o tema ultrapassaria largamente o intuito deste trabalho.

Para uma melhor compreensão desta abordagem diferencial, far-seá um resumo prévio das duas histórias.

\section{Breve resumo}

A fábula de Píramo e Tisbé

Píramo e Tisbé são dois jovens vizinhos, naturais da cidade de Babilónia, que vivem uma intensa história de amor contrariada pelas respectivas famílias. Na impossibilidade de se encontrarem, eles comunicam por gestos ou trocam breves mensagens através de uma fissura numa parede comum. Um dia, marcam um encontro, à noite, junto da sepultura de Nino, escondidos debaixo de uma árvore, perto de uma fonte fresca. O tempo que decorre até à hora combinada parece-lhes longo.

Tisbé aparece em primeiro lugar e, enquanto espera o amado, aparece no local uma leoa com os lábios ensanguentados por ter atacado anteriormente uns bois. Receosa, a jovem corre e refugia-se numa gruta mas, entretanto, deixa cair o véu que o felino se apressa a rasgar.

Quando Píramo chega e vê o véu desfeito e manchado de sangue, pensa que Tisbé morreu, beija desconsolado o acessório da amada e espeta a sua espada nas entranhas. Os frutos da árvore, alimentados com o seu sangue, tornamse então vermelhos.

Regressada ao local, Tisbé depara-se com Píramo desfalecido, que lhe morre nos braços. Nesse instante, a jovem põe fim à vida com a mesma 
espada. Os pais dos dois jovens, desgostosos, sepultam-nos numa urna comum e pedem à árvore que ela produza frutos vermelhos e escuros como prova de luto.

\section{A Rosa do Mato}

A Rosa do Mato, conta os amores de um casal índio, Araciba e Guassu. Eles vivem felizes e despreocupados numa pequena aldeia da floresta brasileira até ao dia em que Guassu é convidado a participar na guerra contra as tribos vizinhas. Indeciso entre o amor e as armas, Guassu, ávido de glória e de reputação, opta enfim pela guerra e ausenta-se durante alguns dias, deixando Araciba triste e amargurada. Depois da partida do amado, a jovem dirige-se muitas vezes ao porto, local de partida e do adeus a Guassu. A certa altura, corre o boato na aldeia de que Guassu morreu e Araciba, desesperada e enlouquecida, acredita ver o espectro do jovem em plena noite. No dia seguinte, vai ao porto para se matar, mas esta tentativa falha e ela transforma-se pouco a pouco num arbusto luxuriante de flores brancas. Quando Guassu regressa da guerra e conhece o destino de Araciba, vai para o porto e chora perto do arbusto. A partir desse instante, as suas visitas ao porto são frequentes. Aí, ele chora perto da planta, cujas flores se tornam, ora vermelhas, ora brancas conforme o momento do dia, e rega-a com as suas lágrimas. Como refere o autor no final,o arbusto podia muito bem chamar-se Araciba e a transformação da cor das flores tem a sua origem nesta história de amor.

\section{Análise comparativa}

A fábula de Ovídio inicia com as filhas do rei Mínias que propõem contar histórias alternadas para suscitar a conversação e tornar mais ligeiro o trabalho da tecelagem enquanto o povo, lá fora, participa no culto a Baco. Elas decidem começar pela história de Píramo e Tisbé, entre as quatro sugeridas. Em Cruz e Silva, pelo contrário, a Rosa do Mato nâo tem antecedentes extra-históricos que mantenham a ligação entre as outras Metamorphoses; ela começa, por assim dizer, abruptamente, sem preliminares explicativos e logo após a Metamorphose VII. Constatamos, no entanto, a presença de uma pequena dedicatória ao destinatário

- "Ao Senhor Lourenço José Vieira Souto" - uma técnica frequente nos textos clássicos. 
A dedicatória introdutiva e o comentário final, no qual o autor confirma a origem de uma tal planta ou de um tal animal depois da história que acaba de contar, são uma estratégia literária do autor cujo fim é assegurar a coesão narrativa das Metamorphoses e dar-lhe um elo de continuidade. A Rosa do Mato é efectivamente um texto etiológico como a fábula de Píramo e Tisbé porque explica a origem de um fenómeno geograficamente localizado, neste caso, o do arbusto brasileiro conhecido por Rosa do Mato. No entanto, o encadeamento das histórias, em ambos os autores, obedece a técnicas narrativas distintas: Ovídio esquece rapidamente os antecedentes que justificam o aparecimento da fábula a partir do momento em que esta começa a ser contada pela filha de Mínias. Cruz e Silva, pelo contrário, abandona qualquer elemento de transição e só a dedicatória a Vieira Souto nos indica o início de uma nova Metamorphose.

O cenário de ambos os textos - um, a cidade de Babilónia; outro, a floresta brasileira - é exótico, mas o de Ovídio remonta a um tempo lonquínquo, remoto, e está ligado a uma civilização antiga. Píramo e Tisbé estão impedidos de se encontrar pelas famílias e esta situação atiça ainda mais o seu desejo físico. De facto, eles ardem de amor e querem unir os seus corpos, como se pode ver no verso 74, quando eles apostrofam a parede separadora: "Paries, quantum erat, ut sineres toto nos corpore jungi, ${ }^{1}$ (Parede, o que te custa deixar unir os nossos corpos?). O mesmo não se passa em Cruz e Silva, onde a acção se desenvolve num país que não remonta à antiguidade clássica, mas numa espécie de paraíso perdido, isento de preconceitos, "no mato fechado", com "erguidos montes" e com "a limpida corrente do rio". Araciba e Guassu podem aí dar livre curso aos seus sentimentos, sem interdições. Também não há nenhuma alusão à dimensão física do amor; é como se os dois jovens índios vivessem uma relação pura, inocente, de tipo platónico. Além disso, ao contrário de Ovídio, eles não vivem um amor secreto porque se deslocam livremente na aldeia, à vista de todos.

O estatuto das personagens e a sua origem sócio-cultural determinam assim maneiras diferentes de viver o amor. Píramo e Tisbé vivem em casas cercadas de muralhas e a fissura num dos muros é a sua única via de comunicação. Por falta de proximidade física ou de contacto verbal, eles falam por gestos e sinais, perdemse em murmúrios, em longos queixumes e falam pateticamente ao muro ou ao

1. OVIDIO. Le Metamorfosi.

2. Silva. Poesias de Antonio Diniz da Cruz e Silva, p. 65, 63, 54 . 
véu. Esta situação de clausura incendia a paixão, motivo pelo qual eles combinam ver-se às escondidas, à noite, perto do túmulo. O tempo psicológico, ao exprimir, no verso 91, a lentidão da passagem do tempo em relação à hora do encontro "et lux tarde discedere" (e a luz pareceu-lhes eclipsar-se tarde) -, revela as restrições a que os jovens estão sujeitos e o seu estado emocional; é o efeito de um estado de interdição. Em contrapartida, Iraciba e Guassu não sofrem qualquer tipo de constrangimento social ou familiar: deslocam-se pela floresta rodeada de montes e habitam uma pequena aldeia perto de um rio de águas límpidas. A beleza do cenário, um verdadeiro locus amoenus, é uma espécie de espelho da natureza pura e inocente do casal apaixonado. Ora, em Ovídio, apenas a área circundante ao túmulo, o local de encontro, é idealizada porque todo o espaço que enquadra a história é fechado, pesado, opressivo. A atmosfera é sombria e tudo deixa prever, desde o início, uma tragédia, que tem lugar precisamente à noite.

Se em Ovídio, é um encontro, o encontro perto do túmulo, que desencadeia os tristes acontecimentos posteriores, em Cruz e Silva é, pelo contrário, a partida de Guassu para a guerra, portanto uma separação, o que desencadeia todos os males seguintes. O aparecimeto da leoa, o véu ensanguentado e o suicídio dos jovens babilónicos são a consequência de uma relação proibida e de encontros às escondidas, assim como o boato da morte de Guassu, a sua morte prematura e a metamorfose de Araciba são a consequência da partida do jovem para a guerra. Isto quer dizer que, quer o véu rasgado, quer o boato na aldeia, são 'malentendidos', são situações que vêm perturbar o decurso normal dos acontecimentos e responsáveis pelo desenrolar infeliz de ambas as histórias.

Não há dúvida que a morte, em Ovídio, é mais cruel e trágica do que em Cruz e Silva: a sucessão das peripécias funestas - o véu manchado de sangue, a decisão imediata de Píramo de matar-se, crendo morta a sua amada, enterrando a espada no flanco e o suicídio posterior de Tisbé com este mesmo objecto, condensados numa única noite, acentuam o carácter trágico da narrativa. Esta unidade de tempo e de acção, típicas da tragédia, não a encontramos no autor português uma vez que a acção principal, que se desenvolve entre a partida e chegada de Guassu, dura uma semana e os dois jovens morrem em momentos diferentes. Digamos mesmo que este autor disfarça ou exorciza a morte de Araciba porque não the faz qualque alusão, limitando-se a dizer que a rapariga, apesar das tentativas de suicídio, se transforma simplesmente em rosa do mato quando pega na flecha para a enfiar no peito: "Então alçando,/Para o peito cravar, o braço e a seta, /Sem o poder dobrar, no ar lhe fica./ Alçado o braço, e nelle a dura seta./As 
plantas quer mover, e as leves plantas/Pesadas se lhe tornão, e se enterrão./Na fria terra; o corpo se adelgaça, / E em viçoso arbusto enfim se torna, /De folhas e alvas flores guarnecido" (123-131). Temos até a impressão de que Araciba não morre, que ela apenas sofre uma metamorfose e é por isso que ela se alegra sempre que Guassu vem fazer-lhe visita. Se não fossem os pássaros nocturnos que piam e as alucinações de Araciba, a visão do fatal espectro (103) de Guassu, não há nenhum momento cruel ou macabro em toda a história que transparece, pelo contrário, doçura, nostalgia e melancolia.

O verdadeiro sentido do arbusto 'rosa do mato' não está contudo isento de uma certa ambiguidade: ele pode representar a própria Araciba, agora um arbusto, como também o seu túmulo, local de peregrinação de Guassu. Concluindo: na fábula Píramo e Tisbé, a árvore é um elemento animizado que sofre como testemunha ocular da tragédia e que, sob ordem dos pais arrependidos, muda a sua cor para vermelho escuro. Tisbé e a amoreira são elementos separados enquanto que Araciba e o arbusto 'rosa do mato' acabam por se confundir. O mesmo se passa nas outras Metamorfoses de Ovídio. Por exemplo, as Éliades, desgostosas com a morte do irmão Faetonte, metamorfoseiam-se em poupos que derramam sangue quando incisos. E Dafné transforma-se em loureiro, graças à intervenção de Júpiter, a fim de poder escapar aos amores de Apólo.

Mas o destino dos dois rapazes é também diferente: Píramo suicidase no mesmo dia de Tisbé enquanto que Guassu não comete esses actos. Ele tem, sim, uma vida breve, curta, gradualmente consumida pelo desgosto, pela saudade da separação e pelas visitas constantes à Rosa do Mato, perto do porto. Este lugar é o correspondente espacial do local de encontro entre Píramo e Tisbé: a "busta Nini" (88), ou o túmulo de Ninus, perto da amoreira. O porto e o túmulo, lugares solitários e afastados, são portanto espaços-chave em cada uma das histórias.

Uma outra diferença a sublinhar diz respeito à voz do narrador. Em Ovídio, o autor esconde-se por detrás de uma das filhas de Mínias; é ela que conta a fábula às irmãs. A presença de algumas sentenças, de frases parentéticas e a expressão "venit ecce recenti /caede leanea", no verso 96 (e eis que, de repente, chega uma leoa), indicando ao ouvinte a chegada da leoa e o princípio da tragédia, remetem justamente para a presença do narrador e, por conseguinte, para a presença do leitor. Temos assim uma espécie de desdobramento: Ovídio esconde-se por detrás da rapariga e o leitor comum esconde-se por detrás das irmãs, ouvintes do conto.

Em Cruz e Silva, o processo é diferente. Ele assume-se como narrador, não se esconde por detrás de uma personagem e, a dada altura, apostrofa 
directamente o leitor com a intenção de o comover, de apelar aos seus sentimentos. Os versos 39 e 40 destinam-se efectivamente a todos aqueles que já viveram o amor; cabe a eles, na verdade, julgar os verdadeiros sentimentos de Araciba e de Guassu: "Vós brandos corações de Amor feridos,/Que em trance igual vos vistes, vós julgai-o". Como Ovídio, ele recorre a frases parantéticas, a verdadeiros comentários pessoais, por exemplo, quando diz "Cousa digna de espanto ao repetirse", ${ }^{3}$ mas vai mais longe do que o autor latino na expressão dos seus sentimentos. Muitos nomes e adjectivos exprimem opinião e subjectividade. Citemos, a título de exemplo, as expressões "desgraçado instante", "amargo pranto", "continuas lagrimas", "carpir-se em altos brados com despiedosas vozes". ${ }^{7}$ É como se o poeta se deixasse levar pela tristeza e sofrimento das personagens, ao ponto de os seus estados de espírito se entrecruzarem e coincidirem.

O receptor da apóstrofe "vós julgai-o" é evidentemente o leitor em geral, mas a história é dedicada a Vieira Souto, a quem o autor se dirige na dedicatória e conclusão. Vieira Souto e as princesas tecedoras, receptores dos textos, desempenham portanto o mesmo papel: a sua presença no interior de cada história, como elementos da meta-história, constitui um processo narrativo que visa à coesão, à estruturação e encadeamento das sequências narrativas.

O amor, por outras palavras, o final trágico entre dois jovens apaixonados é, no entanto, o nó central da história em ambos os autores. As personagens sofrem a dor da separação e confessam pateticamente os seus sentimentos a seres inanimados, processo este que embeleza a narrativa, tornandoa também mais viva e dramática. No final de contas, nenhum dos dois amores se pôde concretizar na vida real e a morte é a única maneira de unir os amantes e torná-los felizes no Além. Elementos igualmente comuns, a árvore animada, objecto de uma metamorfose, e a morte de um ou dos dois amantes. Conclui-se então que o conto Rosa do Mato é o efeito de uma contaminatio uma vez que ele resulta de um conjunto de influências que provêm das Metamorphoses de Ovídio. Porém, as diferenças entre ambos os escritores são maiores do que as semelhanças, como pudemos constatar.

3. Silva. Poesias de Antonio Diniz da Cruz e Silva, p. 179.

4. Silva. Poesias de Antonio Diniz da Cruz e Silva, p. 9.

5. SILVA. Poesias de Antonio Diniz da Cruz e Silva, p. 32.

6. SILVA. Poesias de Antonio Diniz da Cruz e Silva, p. 48.

7. Silva. Poesias de Antonio Diniz da Cruz e Silva, p. 88-89. 


\section{Porquê as diferenças?}

Ambos os autores estão muito afastados no tempo - um nasceu no século I a.C e outro no século XVII - e esta distância temporal implica evidentemente contextos diferentes.

Parece que Cruz e Silva se baseia na obra do poeta latino para explicar a origem de algumas plantas e animais exóticos do Brasil. Trata-se, muito possivelmente, de um processo literário com um intuito estético, destinado ao embelezamento do texto. É como se Cruz e Silva tivesse recorrido ao topos ovidiano da metamorfose para escrever um conjunto de doze histórias a título de brincadeira, para distrair os amigos. Nota-se de facto a relação de amizade, no conto, entre o narrador e o destinatário porque as palavras finais a Vieira Souto são simples e afectivas.

Ao recorrer à dedicatória e ao diálogo final com o destinatário, Cruz e Silva resolve uma técnica narrativa e, ao mesmo tempo, confere à sua história um tom familiar. Portanto a Rosa do Mato nunca poderia ter a natureza dramática da fábula de Píramo e Tisbé, senão ela perderia a empatia emotiva e natural entre o narrador e o seu destinatário. Por isso o poeta português se afasta da tragédia e se aproxima do conto, da narrativa amorosa, na qual o amor se cruza com as armas e na qual as peripécias sentimentais se misturam com as façanhas guerreiras (apenas esboçadas) do herói Guassu. Este tipo de textos destina-se na época, como sabemos, a uma burguesia aisée, ávida de distracção através do prazer da leitura.

O diálogo afectivo com o leitor, os comentários subjectivos assim como a personagem do índio, o 'bom selvagem' do novo continente, e a sua caracterização idealizada são elementos da literatura romântica. Guassu, cujo nome significa 'grande' en tupi-guarani, é "o mais destro e o mais robusto" da aldeia; Araciba - 'araci' quer dizer a 'menina do dia', a 'aurora' - "era della a mais formosa". O cenário é igualmente belo, natural e grandioso, atributos espaciais estes ligados ao "condoreirismo" sul-americano, à atitude de exaltação e pasmo perante uma natureza virgem e imponente. Podemos então afirmar que Cruz e Silva, fascinado pela paisagem brasileira, retoma alguns elementos que constituem tópicos do romantismo deste país. Como sabemos, o poeta desloca-se frequentemente ao Brasil, onde se ocupa de assuntos judiciais, tendo mesmo participado no inquérito que condenou os principais intervenientes da Inconfidência Mineira, em 1789.

Deste modo, Cruz e Silva é permeável, em termos conceptuais, a coordenadas românticas mesmo se, sob o ponto de vista formal, ele se mantém 
um neo-clássico porque o seu vocabulário e a sua construção sintáctica são latinizados e a sua linguagem é cuidada e erudita. No final de contas, Cruz e Silva é sempre um europeu ligado aos modelos literários do velho continente.

Talvez uma outra influência (voluntária ou não) tenha participado na elaboração da Rosa do Mato: a das cantigas de amigo. Como sabemos, um das características destes poemas medievais é a tristeza e a saudade da rapariga que chora o amado, ausente no mar ou no 'fossado'. Às vezes ela fala com o oceano, lamenta-se e pede-lhe notícias. Ora estes mesmos elementos encontram-se genericamente na narrativa de Cruz e Silva.

A Rosa do Mato parece ser assim o produto final de três influências: a clássica, sobretudo a ovidiana, a romântica e a trovadoresca peninsular.

\section{Cruz e Silva's A rosa do mato: the presence of Ovidio}

Abstract: This work is a comparative analysis between the Metamorphosis from Cruz e Silva (1731-1799), called Rosa do Mato, and the fable Pyramus and Thisbé, from the Metamorphosis of Ovidius. The aim is to know the context of the fulfilment of the Rosa do Mato, the motivations that explain the differences between the portuguese poet and his latin model. Several aspects will be analysed: the process of the narrative sequence of each one of the histories and the narrative technics; the scenario, in this case Babylon and the brasilian forest; the person's status; the narrator's voice; the final denouement and the sens of the metamorphosis in both texts. Finally, I will talk about the live context of Cruz e Silva and the influences that determined his options: his live in Brasil and the intersection of brasilian romantism with neoclassicism and the medieval lyrics.

Keywords: Ovidio, Cruze Silva, Portuguese Literature 
O eixo e a roda: v. 19, n. 2, 2010

\section{Referências}

Edições completas

PUBLIO OVIDIO NASONE. Le metamorfosi. Milano: Mondadori, 2007. 2 v.

SILVA, Antonio Diniz da Cruz e. Poesias de Antonio Diniz da Cruz e Silva. Lisboa: Imprensa Régia, 1814.

Obras teóricas

LOPES, Óscar; SARAIVA, António José. História de literatura portuguesa. Porto: Porto Editora, 1982.

OliveIRA MARQues, A. H. de. História de Portugal. Lisboa: Editorial Presença, (1995), 2003. 